TI 2018-093/VIII

Tinbergen Institute Discussion Paper
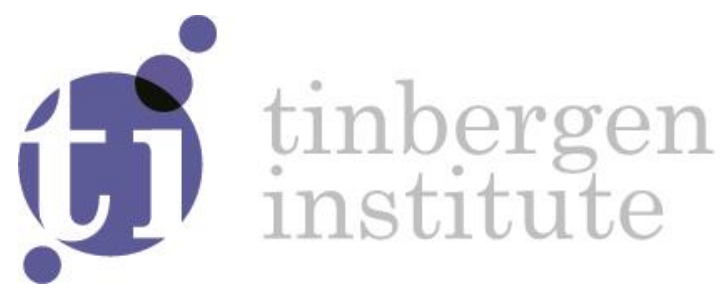

\title{
Conservation auctions, collusion and the endowment effect
}

Justin Dijk ${ }^{1,2}$

Erik Ansink ${ }^{2}$

Daan van Soest ${ }^{3}$

${ }^{1}$ PBL Netherlands Environmental Assessment Agency

2 Vrije Universiteit Amsterdam, the Netherlands

3 Tilburg University 
Tinbergen Institute is the graduate school and research institute in economics of Erasmus University Rotterdam, the University of Amsterdam and VU University Amsterdam.

Contact: discussionpapers@tinbergen.nl

More TI discussion papers can be downloaded at http://www.tinbergen.nl

Tinbergen Institute has two locations:

Tinbergen Institute Amsterdam

Gustav Mahlerplein 117

1082 MS Amsterdam

The Netherlands

Tel.: +31(0)205984580

Tinbergen Institute Rotterdam

Burg. Oudlaan 50

3062 PA Rotterdam

The Netherlands

Tel.: +31(0)10408 8900 


\title{
Conservation auctions, collusion and the endowment effect*
}

\author{
Justin Dijk ${ }^{\dagger}$ Erik Ansink, Daan van Soest ${ }^{\S}$
}

November 19, 2018

\begin{abstract}
We contribute to the literature on the optimal design of auction mechanisms for the procurement of nature conservation activities. We use an economic experiment to examine whether the market efficiency of conservation auctions increases or decreases with repetition. Theory predicts that repetition facilitates collusion among sellers in procurement auctions, while behavioral economics suggests that repetition may increase market efficiency because it attenuates the endowment effect - the phenomenon that ownership of a good tends to increase one's valuation of the good. We find that of these two countervailing effects, the latter has the upper hand; average bids decrease monotonically over the consecutive auctions. Since repetition increases market efficiency, conservation contracts can be of shorter duration and procured at a higher frequency than has been suggested before.
\end{abstract}

JEL Classification: C91, D44, H57, Q57

Keywords: Auctions, procurement, endowment effect, collusion, nature conservation

*We thank participants of the Summer School in Experimental Auctions at the University of Bologna, Bertinoro, session participants at the 2013 BIOECON Conference, Kings College, Cambridge, session participants at the 2014 WCERE Conference, ITU, Istanbul, as well as Jetske Bouma, Timo Goeschl, Andreas Lange, Jason Lusk, Grischa Perino, Charles Plott, and Arthur Schram for helpful suggestions and discussions.

${ }^{\dagger}$ Institute for Environmental Studies, Vrije Universiteit Amsterdam, and Netherlands Environmental Assessment Agency.

†Department of Spatial Economics, Vrije Universiteit Amsterdam, and Tinbergen Institute.

${ }^{\S}$ Department of Economics and CentER, Tilburg University. 


\section{Introduction}

Over the past two decades, conservation procurement auctions have gained prominence as an instrument to implement nature protection programs. Auctioning of nature conservation contracts is already quite common in Australia (Rolfe et al. 2009; Rolfe et al. 2018), and the mechanism has been implemented in countries like the United States (Kirwan et al. 2005; Selman et al. 2008) and Canada (Brown et al. 2011). Also the European Union is increasingly making use of procurement

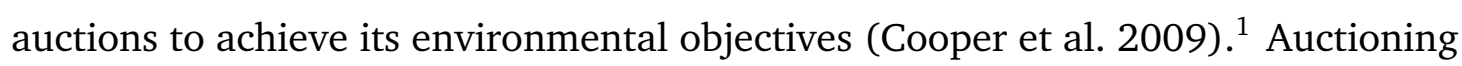
conservation contracts is especially deemed attractive because competitive bidding is expected to increase the cost-effectiveness of nature conservation programs.

Many design aspects affect the efficiency of conservation auctions (Unay-Gailhard and Bojnec 2016), one of which is the duration of the contract (Blackmore and Doole 2013; Rolfe et al. 2018). Obviously, contract periods should be sufficiently long if the environmental returns on conservation investments materialize only with a delay. But economic considerations also play a key role in determining the optimal contract length. On the one hand, longer contract periods imply less frequent contract renewal. This may increase the cost-effectiveness of the auction instrument. In a repeated setting, landholders can condition their bids on past realizations in previous auctions (Latacz-Lohmann and Schilizzi 2005). Such collusion is more likely to happen the more frequent conservation auctions take place. On the other hand, longer contract periods have also been identified as one of the most important causes of low participation rates, especially if farmers are uncertain about (the consequences of) the restrictions that will be placed on their land (Siebert et al. 2006; Ahnström et al. 2009; Blackmore and Doole 2013). The longer the contract period, the more risky the conservation contract becomes. Even if there is no uncertainty about the contract payment, a myriad of factors can change over time that affect the opportunity costs of conservation services. Shorter contract lengths may thus either be conducive or detrimental to the cost-effectiveness of the auction mechanism. Conducive, because shorter contract periods may increase participation rates, and hence the auction's competitiveness. But possibly also detrimental, because shorter contract periods imply more frequent contract renewals, and hence more opportunities for collusive behavior.

\footnotetext{
${ }^{1}$ For a recent overview of the use of conservation tenders, see Rolfe et al. (2018).
} 
In this paper, we experimentally test whether repetition results in increased collusion in procurement auctions, and hence in declining efficiency. We do so by means of a laboratory experiment in which subjects have the opportunity to participate in an auction in which they can sell an item they have just been endowed with. Starting from the notion that shorter contracts imply more frequent interactions, we observe how the bids submitted (i.e. the 'asks') evolve over the interaction in our laboratory experiment. Theoretically, collusion should increase with repetition not just in standard buyer auctions, but also in procurement auctions (Laffont and Tirole 1990). The two types of auctions are mirror images, and hence the prediction is that the average amount of compensation asked in procurement auctions should increase over time. This conjecture is strengthened by a wealth of experimental evidence indicating that collusion indeed increases in standard buyer auctions (with one seller facing many buyers). If we fail to find evidence for asks increasing with repetition, shortening contract periods may give rise to an unambiguous increase in auction efficiency.

Our laboratory experiments are set up as follows. The main treatment is one in which potential sellers, seven in a group, can submit bids on how much they need to receive to sell an item. Asking subjects to consider what price they need to receive to sell their item may better capture the thought process associated with being asked to accept (far-reaching) changes in land use (including the imposition of land use restrictions) than more abstract approaches like induced-value designs. Building on the earlier literature in economics (especially Kahneman et al. 1990) we endow our subjects with a coffee mug. Subjects in our main treatment participate in ten auctions, in each of which they need to (re-)consider what price they ask for their coffee mug. Subjects always interact with the same six other potential sellers. In every auction the bids of the four lowest bidders are accepted, and the payment each of the four winning bidders receives is equal to the amount of money she asked for in that auction.

We find no evidence that repetition gives rise to increasing bids. While this is comforting news for policy makers, it cannot be the final answer that nature conservation agencies can shorten their contracts, for two reasons. First, lab-experimental evidence may point towards ways how to solve real-world (policy) problems, but it would be hazardous to ruthlessly implement a policy change without additional pretesting 
in the form of, preferably, a field experiment - see also below. $2^{2}$ Second, and very pertinent to our paper, the absence of an upward trend in asks may not be evidence of absence of collusion. One key confounding factor is that ownership status has been found to affect people's valuation, causing willingness to accept to sell an item to be typically much higher than the willingness to pay to acquire an item (cf. Kahneman and Tversky 1979; Kahneman et al. 1990; Horowitz and McConnell 2002). This 'endowment effect' may affect our subjects' initial valuation of the item we endow them with, but previous research also showed that this effect tends to attenuate over time (see for example Shogren et al. 1994 and List 2003). Collusion may thus cause bids to increase over time, but attenuation of the endowment effect may cause them to fall. We isolate the collusion effect by implementing two additional treatments. We find that indeed repetition attenuates the endowment effect, but we find no evidence of increased collusion.

We are not the first to use lab experiments to answer agro-environmental policy questions. As argued by Noussair and van Soest (2014) and Colen et al. (2016), laboratory experiments can be an important first step in the development of effective policy making in domains where experimentation in the field is costly and hazardous, or where observational data are not very informative because policy impacts may be obscured by self-selection effects. Indeed, as discussed by Colen et al. (2016), there is a growing body of lab-experimental research aimed at test-bedding policies in the agro-environmental domain. Parkhurst et al. (2002) and Parkhurst and Shogren (2005, 2007) use laboratory experiments to test whether financial incentives can be effective in coordinating land use decisions to create contiguous nature conservation areas. Banerjee et al. (2012) and Banerjee et al. (2014) use laboratory experiments to test how coordination failure is affected by group size and by the amount of information provided. Kesternich et al. (2014) and Bouma et al. (2019) use laboratory experiments to see what revenue-sharing rules are most conducive to achieving conservation success in the presence of group contracts. Finally, Cramton et al. (2018) use laboratory experiments to test the cost-effectivenss of alternatives to the US Conservation Reserve Program's current auction design.

Lab experiments have thus been used to shed light on how behavioral predispositions affect public good provision decisions in the presence of (different) finan-

\footnotetext{
${ }^{2}$ Such field experiments would also capture other factors that influence participation and behavior in conservation contracts (Unay-Gailhard and Bojnec 2016).
} 
cial stimuli, but the laboratory has also been used quite intensively to test-bed the (optimal) design of auction mechanisms. Cason and Gangadharan (2005) used a laboratory experiment to compare the efficiency of uniform and discriminative price auctions for reducing non-point source pollution (see also Cason and Gangadharan 2004). Schilizzi and Latacz-Lohmann (2013) combined theory with a laboratory experiment to test the performance of budget-constrained conservation tenders. Kawasaki et al. (2012) used laboratory experiments to compare bidding behavior and auction performance under discriminatory-price and uniform-price auctions in an imperfect monitoring environment. Banerjee et al. (2015) analyzed how information about the regulator's objectives affects student subjects' bidding behavior and auction performance. Our study complements this line of research by test-bedding the extent to which collusion and the endowment effect affect the efficiency of the auction mechanism in a repeated interaction, providing a first modest step in this chain of testing whether a shorter contract period (and hence a higher frequency of interaction) reduces market efficiency: $:^{3}$

The setup of this paper is straightforward; we present the experimental design in Section 2 and the results in Section 3. Section 4 concludes.

\section{Experimental design}

The set-up of our main treatment, a discriminatory price procurement auction, is as follows. Upon entering the experimental session, subjects were randomly assigned to groups of seven, and each subject was provided with an item that was, in principle, hers to keep - a high-end thermos coffee mug. Subjects could, however, decide to

\footnotetext{
${ }^{3}$ Obviously, the usefulness of laboratory experiments as a test-bed for policy making depends on the extent of their external validity (Camerer 2015). Laboratory experiments have been proven very useful in the design of buyer auctions, because they tend to well-predict behavior in the field. Because of this reason, many laboratory experiments have been run to test the impact of design issues like the optimal number of participants in buyer auctions, on the impact of providing buyers with seller value information, and on the consequences of sequential (or repeated) auctions. Brookshire et al. (1987) and List and Shogren (1998) run experiments on the buyers' side of the market, and find evidence in favor of the external validity of laboratory experiments. Because procurement auctions are mathematically identical to standard buyers' auctions, one would expect the lab to also have high external validity when it comes to design issues for procurement auctions. Indeed, Cason et al. (2003) document a fair amount of external validity in their experiment with students and farmers in Victoria, Australia. Still, our paper should be viewed as providing only a first step in testing how repetition affects collusion in real-world conservation auctions, paving the way for a field experiment to delve deeper into the behavioral mechanisms behind bidding behavior.
} 
offer their coffee mug for sale, by indicating the amount of money they wanted to receive to be willing to sell their mug. In each auction, all seven bids (or better, 'asks') were ranked from lowest to highest, and the four lowest asks were accepted. Subjects would participate in ten consecutive auctions, and they were informed about this rule beforehand. We also informed them that at the end of the session the computer would randomly select one auction, and all the trades in that auction would be implemented. When a subject's bid was accepted in the auction that was selected by the computer, she had to sell her coffee mug, and the amount she received would be equal to the ask she had submitted in that auction. This auction is a procurement auction because subjects are on the sellers' side of the market, and hence they need to think about the amount of money they want to receive for their item, taking into account the (expected) bidding behavior of the other subjects in their group. And it is a discriminatory price auction because if a subject's bid is accepted, she receives an amount equal to the payment amount she asked for in her bid.

We now discuss the design in more detail. The setup chosen is such that our subjects' decisions have actual consequences. The high-end thermos coffee mug was made of aluminum, carried a university logo, and it used to be sold at the university's gift shop for $€ 12.95$ a piece. At the time of the experiment, however, its production had been discontinued. Hence, subjects who left the experiment with a mug could not return it to the gift shop in exchange for money. Subjects were not informed of the mug's retail price, but we did inform them that the mug was no longer available for purchase. After all subjects received a package containing their mug, they were invited to open it and inspect its contents.

Having received their coffee mug, subjects were informed that they would have the opportunity to sell the mug back following the above procedure. Upon having submitted their ask, subjects were shown the following script on screen: "My bid in the auction is $€ X$. If my bid is among the four lowest bids in my group, I sell my mug for the price stated in my bid. Otherwise, I keep my mug", and then they were asked to enter their bid $X$. Subjects could enter any value between $€ 0.00$ and $€ 15.00$ rounded to tens of Euro cents.

We were interested in observing how asks would evolve with repetition, but subjects only had one mug to keep or sell. We informed our subjects that they would participate in ten consecutive auctions. In each of the ten auctions they could submit an ask, and at the end of the session the computer would randomly select one 
auction of which the outcome would be implemented. We used a strong visual aid to emphasize that the outcome in each auction would have actual consequences in case the auction would be selected for implementation. If their bid was among the four lowest bids in that auction, subjects would be shown a picture of the coffee mug on their screen with a large red cross on top, accompanied by the following text: "Your bid has been ACCEPTED. If this auction is selected by the computer at the end of the experiment, you sell your mug for [the subject's bid], and you have to hand it in". If their bid was not among the four lowest in a specific auction, subjects were shown the picture of the mug without a cross, and the accompanying text would be: "Your bid has NOT been accepted. If this auction is selected by the computer at the end of the experiment, you take your mug home". Although the mug remained on their desks throughout the experiment, subjects would be aware that if this auction were to be selected, the mug would be theirs if their bid was not accepted, and vice versa. We implemented random tie-breaking in case the fourth and fifth lowest bids were the same.

Our primary interest is to test whether repetition gives rise to collusion. We expected to observe collusion in this treatment because of two design decisions. First, Knetsch et al. (2001) show that higher shares of accepted bids facilitate collusion. In each auction we accepted four of the seven bids, which is considered to be a high ratio. Second, we provided subjects with full information on the bids submitted by the other participants in their group, ranked from highest to lowest.

These design decisions are expected to foster collusion, but non-increasing bids are no conclusive evidence that repetition does not invite increased collusion. Subjects were endowed with an item, and repetition may not just invite collusion, it may also attenuate the endowment effect (Shogren et al. 1994; List 2003). We separate the two effects by implementing two additional treatments, $U$-endowed and $U$-unendowed. Here, we follow the protocol of Kahneman et al. (1990). Treatment U-endowed is identical to treatment $D$, except that we buy back all mugs that are offered at a price below or equal to a specific strike price. The strike price is predetermined, differs between auctions, and its value is only revealed to the participants after they have submitted their asks. This mechanism is typically referred to as a Uniform Price Auction (Vickrey 1961). Bidding one's true value is the dominant strategy, as none of the bids affect the sales price; they only affect whether one's bid is accepted, or not. Suppose that one's true valuation happens to be below the (yet undisclosed) strike 
price. Overbidding does not yield any benefits compared to bidding one's true value (if the ask submitted turns out to still be lower than the predetermined strike price), but it may make the decision maker worse off (if the ask submitted turns out to be higher than the predetermined price, so that the bidder forgoes a profitable trade). The time pattern of the bids thus reflects how subjects' valuation of the mug changes over the auctions - possibly because of the (attenuation of the) endowment effect. The predetermined price to which bids are compared, is the same for all participants in a group. We keep price feedback constant by matching groups in $D$ and $U$-endowed using the values of the fourth price path in the ten auctions of a $D$ group as the sequence of exogenous strike prices for the ten auctions of a matched $U$-endowed group (cf. Offerman and Potters 2006).

Next, treatment $U$-unendowed is identical to $U$-endowed, except that subjects were shown the mug, but they did not yet receive it. After subjects were seated at their cubicles, the experimenter passed around one single mug for the subjects to examine at their leisure. When all subjects had finished inspecting the mug, it was put on display at a central location in the computer lab. All other mugs were kept, fully packaged, in the front of the laboratory. The decision subjects had to make was to submit the price at which they are indifferent between receiving the money, or the mug. If the predetermined strike price - which is the value of the fourth price in one of the $D$ group in the same auction, as was the case in U-endowed - is above the respondent's indifference point, she would sell the item and receive the predetermined price. if the predetermined price was below her indifference point, she would keep her mug.

The (dynamics of the) endowment effect is measured by comparing the average bids under U-endowed and U-unendowed, and (the dynamics of) collusion is measured by comparing the average bids under $D$ and $U$-endowed.

Ours is a between-subject design, but groups can be matched according to the price feedback they received. So for each comparison we have six matching pairs. Assuming an average bid for the mug in U-endowed of 5 Euro's and a 2 Euro standard deviation, the paired setup of the three treatments allows us to detect a 2 Euro price difference with $80 \%$ probability.Our test is thus adequately powered.

Although the decisions to be taken are fairly straightforward, our treatment estimates may be contaminated by our subjects' differential levels of understanding the tasks assigned in each of the three treatments. To gauge the impact of this, subjects 
were offered a second task at the end of the session. This second task consisted of a one-shot auction using the same auction design ( $D$, U-endowed, or U-unendowed) as the treatment they had participated in before. The only difference is that now a 'virtual token' is auctioned instead of a mug. Subjects were informed what amount of money they would receive if they would end up owning a virtual token (the so-called induced value), and were subsequently asked to make their bid. The purpose of this induced value auction is to check whether subjects had understood the auctioning mechanism. The prediction is that subjects would bid higher than their induced value under $D$, but that they would exactly bid their induced value under $U$-endowed and U-unendowed.

The experiment was implemented in Tilburg University's CentERLab in a computerized environment using z-Tree (Fischbacher 2007). A sample of the instructions is presented in the Appendix. In total, 42 student subjects participated in each of the three treatments, and none of these subjects participated in more than one treatment. All 126 subjects were students at Tilburg University with different nationalities and different academic backgrounds (economics, legal studies, management, social sciences), and were recruited using a mailing list. Each subject received a show-up fee of $€ 5$. Each session lasted about 75 minutes.

\section{Results}

Tables 1 and 2 as well as Figure 1 present our main results. We find substantial treatment effects on bidding behavior. Table 1 shows that bids, averaged over all subjects and over all ten auctions, were highest under $D$ and lowest under $U$-unendowed. This is as expected because subjects should bid higher than their true reservation price in the discriminatory price auction (which explains the difference in average bids between $D$ and $U$-endowed), while the bids in U-endowed should be higher than those in $U$-unendowed because of the endowment effect. With respect to the number of mugs sold, we find that on average one more mug was sold under $U$-endowed and two more mugs under $U$-unendowed compared to the exogenously imposed sale of four mugs under $D$.

Using groups in different treatments with the same sequence of strike prices as matched pairs, Table 2 shows that average bids in $D$ were significantly different from those in $U$-unendowed ( $p=0.028$ according to a Wilcoxon matched pairs test 
Table 1: Average bids and average number of mugs sold by treatment (standard deviations are presented in parentheses).

\begin{tabular}{lccc}
\hline & $\mathrm{D}$ & U-endowed & U-unendowed \\
\hline Average bid (SD) & 7.22 & 5.81 & 3.25 \\
& $(1.56)$ & $(2.47)$ & $(0.91)$ \\
Average number of mugs sold (SD) & 4 & 4.97 & 6.25 \\
& $(0)$ & $(1.34)$ & $(0.98)$ \\
\hline Observations & 6 & 6 & 6 \\
\hline
\end{tabular}

Table 2: Treatment effects.

\begin{tabular}{lcc}
\hline & $\begin{array}{l}\text { Difference } \\
\text { in average bids }\end{array}$ & $\begin{array}{c}\text { Wilcoxon matched pairs } \\
\text { test on groups ( } p \text { value) }\end{array}$ \\
\hline D vs. U-endowed & 1.41 & 0.075 \\
$\begin{array}{c}\text { (collusion) } \\
\text { D vs. U-unendowed }\end{array}$ & 3.97 & 0.028 \\
$\begin{array}{c}\text { U-endowed vs. U-unendowed } \\
\text { (endowment effect) }\end{array}$ & 2.56 & 0.075 \\
\hline
\end{tabular}

on groups with $N_{1}=N_{2}=6$ ). Hence, we find evidence for a combined impact of collusion and the endowment effect on bidding behavior. In particular, we find that collusion is a significant driver (at the 10\% level) of bidding behavior ( $D$ vs. $U$-endowed; $p=0.075$ according to a matched-pairs Wilcoxon test, with $N_{1}=N_{2}=6$ ), and that the endowment effect has a significant (10\% level) impact on the willingness to accept to part with the mug (U-endowed vs. U-unendowed, $p=0.075$ according to the appropriate Matched-pairs Wilcoxon test, again with $N_{1}=N_{2}=6$ ).

Figure 1 shows the average bids per treatment over the ten consecutive auctions. Visual inspection of the bids in $D$ shows no sign of bidders coordinating on higher bids in later auctions. On the contrary, bids under both $D$ and $U$-endowed decrease monotonically and, if anything, tend to converge. Bids under $U$-unendowed appear to be more stable over the repeated auctions. This is consistent with subjects' having established how much the mug is worth to them early on in the experiment, and realizing they have no reason to revise their valuation because no new relevant information is forthcoming in subsequent auctions.

The results of this visual inspection are confirmed by the statistical tests presented in Table 3. In this table we compare, for each of the three treatments, the average 


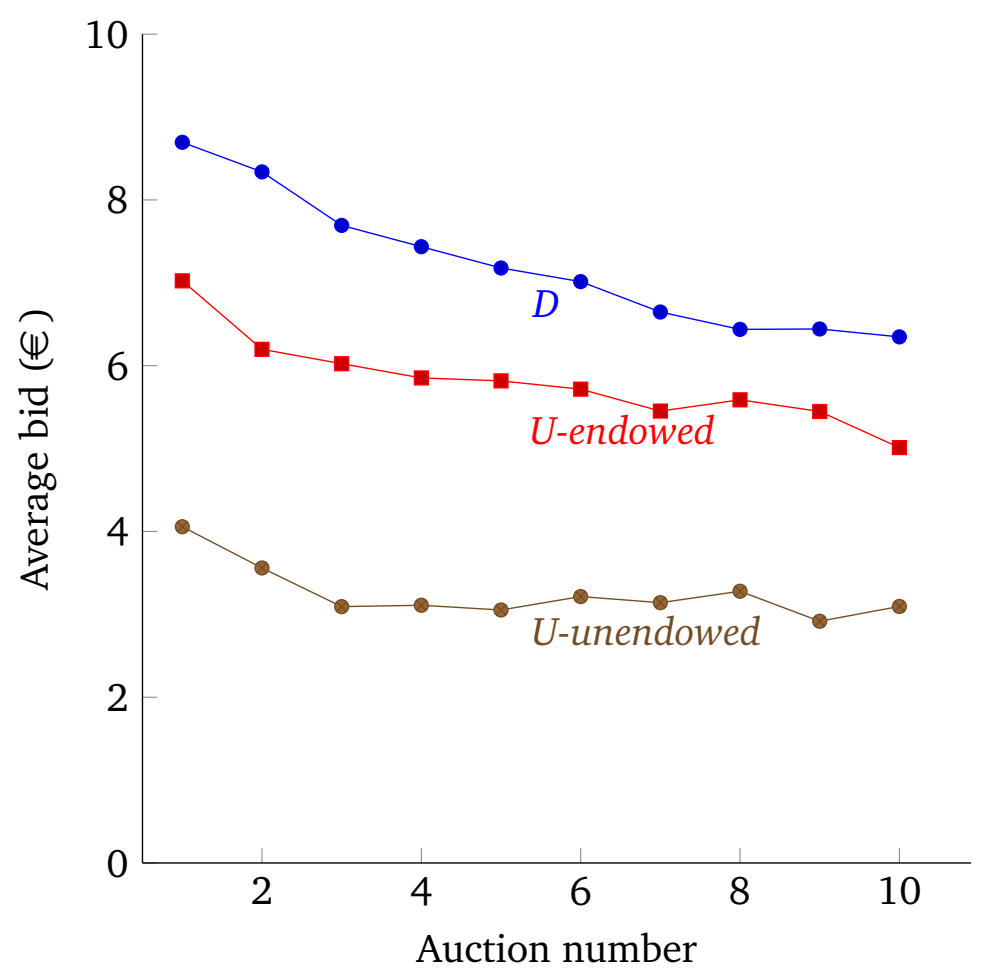

Figure 1: Average bids over the auctions by treatment.

bids at the beginning of the auctions (auctions 1 and 2) to those at the end (auctions 9 and 10). We find attenuation of both collusion and the endowment effect. Repetition causes average bids in $U$-endowed to fall over time, a decrease that is only strengthened in $D$ (Wilcoxon matched pairs test on auctions, $p<0.05$ for both tests). The decrease in bids in $U$-unendowed between the first two and last two auctions is relatively small and fails to be statistically significant at conventional significance levels (Wilcoxon matched pairs test on auctions, $p=0.116$ ).

To assess the development of bids in more detail, we run two regression models. The first model, presented in equation (1) below, allows for a non-linear relationship

Table 3: Average bids in first two vs. last two auctions by treatment.

\begin{tabular}{lccc}
\hline & $\begin{array}{l}\text { Bids in } \\
\text { rounds } 1 \text { and } 2\end{array}$ & $\begin{array}{l}\text { Bids in } \\
\text { rounds } 9 \text { and } 10\end{array}$ & $\begin{array}{l}\text { Wilcoxon } \\
\text { matched pairs test ( } p \text { value) }\end{array}$ \\
\hline $\mathrm{D}$ & 8.52 & 6.40 & 0.028 \\
U-endowed & 6.61 & 5.23 & 0.035 \\
U-unendowed & 3.81 & 3.01 & 0.116 \\
\hline
\end{tabular}


Table 4: GLS estimation results of individual bids.

\begin{tabular}{lcc}
\hline & Model $(1)$ & Model $(2)$ \\
\hline$\beta_{1}, \beta_{1}^{\prime}$ & $-0.345^{* * *}$ & $8.442^{* * *}$ \\
& $(0.056)$ & $(0.125)$ \\
$\beta_{2}, \beta_{2}^{\prime}$ & 0.004 & $6.590^{* * *}$ \\
& $(0.005)$ & $(0.093)$ \\
Constant & $9.028^{* * *}$ & \\
& $(0.159)$ & \\
\hline Observations & 420 & 420 \\
Wald $\chi^{2}$ & 264 & 8159 \\
\hline
\end{tabular}

Standard errors in parentheses; ${ }^{* * *}$ indicates $p<0.01$.

between bids and auction number. The second model, presented in equation (2), estimates an asymptote for the bids as well as the convergence process towards that asymptote.

$$
\begin{aligned}
& \operatorname{bid}_{i, t}=\beta_{0}+\beta_{1} t+\beta_{2} t^{2}+\mu_{i, t}, \\
& \operatorname{bid}_{i, t}=\beta_{1}^{\prime}\left(\frac{1}{t}\right)+\beta_{2}^{\prime}\left(\frac{t-1}{t}\right)+\mu_{i, t} .
\end{aligned}
$$

In these specifications, $\operatorname{bid}_{i, t}$ is the amount bid by subject $i$ in auction $t$, the $\beta$ 's are the coefficients to be estimated, and $\mu_{i, t}$ is the random error term distributed normally with mean zero. Model (1) is a standard quadratic regression model, implying that the auction with maximum efficiency (from the auctioneer's perspective) is equal to $t=-\beta_{1} / 2 \beta_{2}$ (if $\beta_{1}<0$ and $\beta_{2}>0$ ). Model (2) is based on Noussair et al. (1995); it assumes that bids converge to an asymptote equal to $\beta_{2}^{\prime}$. Note that this model does not have an intercept, and that the relative weight of $\beta_{1}^{\prime}$ to $\beta_{2}^{\prime}$ is largest in the earlier auctions, while it becomes smaller and smaller in the later auctions, and vice versa. We use models (1) and (2) to estimate the pattern of bids in $D$ using Generalized Least Squares (GLS) with residuals that are robust for subject-specific AR(1) processes as well as heteroscedasticity ${ }^{4}$

Table 4 presents the results of the two regression models. Model (11) fails to provide support for a U-shaped relationship between auction number and bids. Its

\footnotetext{
${ }^{4} \mathrm{~A}$ Wooldridge test for autocorrelation in panel data rejects the null of no first-order autocorrelation in the residuals for both specifications. The likelihood ratio test for nested models rejects the null of no heteroscedasticity in the residuals, again for both specifications.
} 


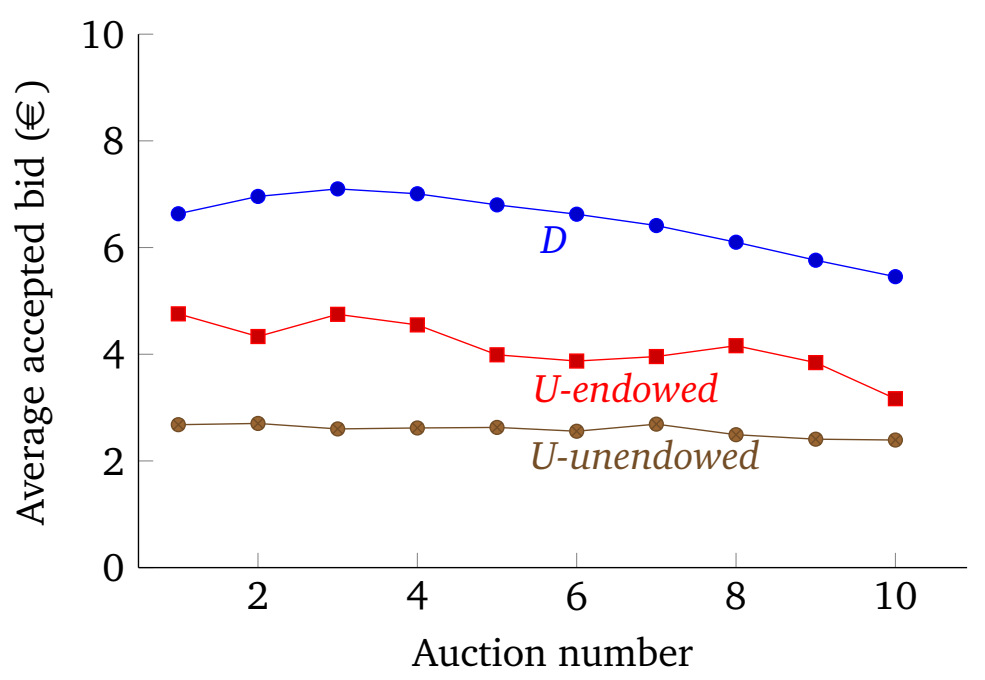

Figure 2: Average accepted bids over the auctions by treatment, compare Figure 1 .

quadratic specification implies that the number of auctions with minimal bids (and hence maximal efficiency) equals $t=44$, which is far out of sample. If anything, given the non-significant $\beta_{2}$ coefficient, this model indicates that bids decrease linearly over the auctions. Model (2) finds that bids converge to a long-run level of about $€ 6.59$, with rather quick convergence in the earlier periods.

We perform two types of robustness checks. First, we analyze whether the above results also hold for the analysis of accepted bids - those cases in which the mug was sold ( $D$ and $U$-endowed) or in which a payment was received (U-unendowed). Figure 2 shows the average accepted bids over the auctions by treatment. Visual inspection of the accepted bids in $D$ suggests that bidders coordinate on higher bids in initial auctions. Comparing the temporal pattern of the average bids (see Figure 1) to that of the average accepted bids (see Figure 2), we observe that the decrease in average bids is caused predominantly by the initially high bidders decreasing their bids in order to become more competitive. Over the interaction, however, we do not only observe the average bid to fall over time, but also the average accepted bid. This shows that collusion was ultimately not sustainable.

Second, we test to what extent imperfect understanding of our subjects may have affected our results. Recall that upon having completed the first experiment with the coffee mugs, subjects participated in a second experiment. This second experiment was a one-shot induced value auction of the same type as the subject participated in in the first experiment. We find that, on average, the difference between a subject's 
bid and her induced value was less than 10 cents (from a range between 0 and 150 cents) in $U$-endowed and $U$-unendowed, and only 2 of the 42 subjects in $D$ submitted a bid below their induced value. We rerun the above analysis using only those subjects who signal that they understood the game - those who bid according to theory in the second experiment. Specifically, this subset consists of subjects for whom the difference 'bid - induced value' was either zero or +1 in U-endowed and U-unendowed as well as subjects whose bid was strictly larger than their induced value in $D$. We find that restricting the analysis to these subjects results in average bids of 7.24, 5.27 and 3.68 in $D$, U-endowed, and U-unendowed, respectively. None of these averages are significantly different from the average bids in the full sample as reported in Table 1. All of the above conclusions based on the full sample also hold for the restricted sample. $5^{5}$ Hence we conclude that the attenuation of both collusion and the endowment effect is not due to imperfect understanding of the auction mechanisms.

\section{Conclusion}

We examined whether the result that repetition reduces efficiency in standard (or oneseller-multiple-buyers) discriminatory price auctions also applies to discriminatory price procurement auctions, where an auctioneer aims to purchase goods or services from multiple sellers. Repetition facilitates collusion in both auction types, but we hypothesized that outcomes may differ for repeated procurement auctions because repetition has been shown to reduce the endowment effect. Results of our experiment show that average bids in the discriminatory price procurement auction fall with repetition. In particular, we do not find evidence for an increase in bids in later auctions. We ran two additional treatments to isolate collusion and the endowment effect, and we find that both decrease with repetition. In other words, the attenuation of both collusion and the endowment effect causes repetition to decrease average bids and thereby increase efficiency to the auctioneer.

Increasing efficiency with repetition is comforting news for governments that want to use repeated discriminatory price auctions for nature conservation (Latacz-

\footnotetext{
${ }^{5}$ Similar to Cason and Plott (2014) we find some evidence for misconception of the BDM method (in our $U$-unendowed treatment), but the number of subjects that do not bid 'optimally' is not significantly different between $U$-unendowed and $U$-endowed (or 'BDM + endowment'). In addition, the average bids of optimally-bidding subjects are not significantly different from those that do not bid optimally, within treatments. Hence, if the number and the level of errors are equal between these treatments, we can attribute the remaining difference in average bids to the endowment effect.
} 
Lohmann and van der Hamsvoort 1998; Latacz-Lohmann and Schilizzi 2005) or other repeated auction types in which the endowment effect could play a role, such as the buyback of fishing licenses (Schilizzi and Latacz-Lohmann 2012; DePiper et al. 2013), or the buyback of irrigation licenses (Iftekhar et al. 2013).

Although the comparative statics of laboratory experiments on auctions tend to generalize to domains outside the laboratory and seem to be fairly predictive of behavior in real-world auctions, it is an open question whether the same holds for our results. This generalization depends in part on whether the 'ownership premium' underlying the endowment effect in the real world (i.e. the sentimental value that landowners attach to their land) is larger or smaller than the premium that student subjects attach to a coffee mug they just received. Field experiments are the next logical step to be taken to test whether indeed repetition increases (rather than decreases) market efficiency, and thus, whether conservation contracts can be shorter and procured at a higher frequency than has been suggested before. 


\section{References}

Ahnström, J., J. Höckert, H. Bergeå, C. Francis, P. Skelton, and L. Hallgren. 2009. "Farmers and nature conservation: What Is known about attitudes, context factors and actions affecting conservation?" Renewable Agriculture and Food Systems 24 (1): $38-47$.

Banerjee, S., A. Kwasnica, and J. Shortle. 2012. "Agglomeration bonus in small and large local networks: A laboratory examination of spatial coordination". Ecological Economics 84:142-152.

- . 2015. "Information and auction performance: A laboratory study of conservation auctions for spatially contiguous land management". Environmental and Resource Economics 61 (3): 409-431.

Banerjee, S., F. De Vries, N. Hanley, and D. van Soest. 2014. "The impact of information provision on agglomeration bonus performance: An experimental study on local networks". American Journal of Agricultural Economics 96 (4): 1009-1029.

Blackmore, L., and G. Doole. 2013. "Drivers of landholder participation in tender programs for Australian biodiversity conservation". Environmental Science \& Policy 33:143-153.

Bouma, J., T. Nugyen, E. van der Heijden, and J. Dijk. 2019. "Analysing group contract design using a lab and a lab-in-the-field threshold public goods experiment". Forthcoming in European Review of Agricultural Economics.

Brookshire, D., D. Coursey, and W. Schulze. 1987. "The external validity of experimental economics techniques: Analysis of demand behavior". Economic Inquiry 25 (2): 239-250.

Brown, L., E. Troutt, C. Edwards, B. Gray, and W. Hu. 2011. "A uniform price auction for conservation easements in the Canadian prairies". Environmental and Resource Economics 50 (1): 49-60.

Camerer, C. 2015. "The promise and success of lab-field generalizability in experimental economics: A critical reply to Levitt and List." In Handbook of Experimental Economic Methodology, ed. by G. Fréchette and A. Schotter. Oxford: Oxford University Press. 
Cason, T., and L. Gangadharan. 2005. "A laboratory comparison of uniform and discriminative price auctions for reducing non-point source pollution". Land Economics 81 (1): 51-70.

— . 2004. "Auction design for voluntary conservation programs". American Journal of Agricultural Economics 86 (5): 1211-1217.

Cason, T., and C. Plott. 2014. "Misconceptions and game form recognition: Challenges to theories of revealed preference and framing". Journal of Political Economy 122 (6): 1235-1270.

Cason, T., L. Gangadharan, and C. Duke. 2003. "A laboratory study of auctions for reducing non-point source pollution". Journal of Environmental Economics and Management 46 (3): 446-471.

Colen, L., S. Gomez y Paloma, U. Latacz-Lohmann, M. Lefebvre, R. Préget, and S. Thoyer. 2016. "Economic experiments as a tool for agricultural policy evaluation: insights from the European CAP". Canadian Journal of Agricultural Economics 64 (4): 667-694.

Cooper, T., K. Hart, and D. Baldock. 2009. "Provision of public goods through agriculture in the European Union". Institute for European Environmental Policy.

Cramton, P., D. Hellerstein, N. Higgins, R. Iovanna, K. López Vargas, and S. Wallander. 2018. "Testbed experiments for improving the cost-effectiveness of the Conservation Reserve Program". Working Paper, University of Maryland.

DePiper, G., N. Higgins, D. Lipton, and A. Stocking. 2013. "Auction design, incentives, and buying back Maryland and Virginia crab licenses". Canadian Journal of Agricultural Economics 61 (2): 353-370.

Fischbacher, U. 2007. "z-Tree: Zurich toolbox for ready-made economic experiments". Experimental Economics 10 (2): 171-178.

Horowitz, J., and K. McConnell. 2002. "A review of WTA/WTP studies". Journal of Environmental Economics and Management 44 (3): 426-447.

Iftekhar, M., J. Tisdell, and J. Connor. 2013. "Effects of competition on environmental water buyback auctions". Agricultural Water Management 127:59-73.

Kahneman, D., and A. Tversky. 1979. "Prospect theory: An analysis of decision under risk". Econometrica 47 (2): 263-292. 
Kahneman, D., J. Knetsch, and R. Thaler. 1990. "Experimental tests of the endowment effect and the Coase theorem". Journal of Political Economy 98 (6): 1325-1348.

Kawasaki, K., T. Fujie, K. Koito, N. Inoue, and H. Sasaki. 2012. "Conservation auctions and compliance: Theory and evidence from laboratory experiments". Environmental and Resource Economics 52 (2): 157-179.

Kesternich, M., A. Lange, and B. Sturm. 2014. "The impact of burden sharing rules on the voluntary provision of public goods". Journal of Economic Behavior and Organization 105:107-123.

Kirwan, B.s, R. Lubowski, and M. Roberts. 2005. "How cost-effective are land retirement auctions? Estimating the difference between payments and willingness to accept in the Conservation Reserve Program". American Journal of Agricultural Economics 87 (5): 1239-1247.

Knetsch, J., F.-F. Tang, and R. Thaler. 2001. "The endowment effect and repeated market trials: Is the Vickrey auction demand revealing?" Experimental Economics 4 (3): 257-269.

Laffont, J.-J., and J. Tirole. 1990. "Adverse selection and renegotiation in procurement". Review of Economic Studies 57 (4): 597-625.

Latacz-Lohmann, U., and S. Schilizzi. 2005. "Auctions for conservation contracts: A review of the theoretical and empirical literature". Report to the Scottish Executive Environment and Rural Affairs Department.

Latacz-Lohmann, U., and C. van der Hamsvoort. 1998. "Auctions as a means of creating a market for public goods from agriculture". Journal of Agricultural Economics 49 (3): 334-345.

List, J. 2003. "Does market experience eliminate market anomalies?" Quarterly Journal of Economics 118 (1): 41-71.

List, J., and J. Shogren. 1998. "Calibration of the difference between actual and hypothetical valuations in a field experiment". Journal of Economic Behavior and Organization 37 (2): 193-205.

Noussair, C., and D. van Soest. 2014. "Economic experiments and environmental policy". Annual Review of Resource Economics 6 (1): 319-337.

Noussair, C., C. Plott, and R. Riezman. 1995. "An experimental investigation of the patterns of international trade". American Economic Review 85 (3): 462-491. 
Offerman, T., and J. Potters. 2006. "Does auctioning of entry licences induce collusion? An experimental study". Review of Economic Studies 73 (3): 769-791.

Parkhurst, G., and J. Shogren. 2005. "Does complexity reduce coordination?" Applied Economics Letters 12 (7): 447-452.

- . 2007. "Spatial incentives to coordinate contiguous habitat". Ecological Economics 64 (2): 344-355.

Parkhurst, G., J. Shogren, C. Bastian, P. Kivi, J. Donner, and R. Smith. 2002. "Agglomeration bonus: An incentive mechanism to reunite fragmented habitat for biodiversity conservation". Ecological Economics 41 (2): 305-328.

Rolfe, J., S. Schilizzi, P. Boxall, U. Latacz-Lohmann, S. Iftekhar, M. Star, and P. O'Connor. 2018. "Identifying the causes of low participation rates in conservation tenders". International Review of Environmental and Resource Economics 12 (1): $1-45$.

Rolfe, J., J. Windle, and J. McCosker. 2009. "Testing and implementing the use of multiple bidding rounds in conservation auctions: A case study application". Canadian Journal of Agricultural Economics 57 (3): 287-303.

Schilizzi, S., and U. Latacz-Lohmann. 2013. "Conservation tenders: Linking theory and experiments for policy assessment". Australian Journal of Agricultural and Resource Economics 57 (1): 15-37.

— . 2012. "Evaluating conservation auctions with unknown bidder costs: The Scottish fishing vessel decommissioning program". Land Economics 88 (4): 658-673.

Selman, M., S. Greenhalgh, M. Taylor, and J. Guiling. 2008. "Paying for environmental performance: Potential cost savings using a reverse auction in program sign-up". WRI Policy Note, World Resources Institute, Washington, D.C.

Shogren, J., S. Shin, D. Hayes, and J. Kliebenstein. 1994. "Resolving differences in willingness to pay and willingness to accept". American Economic Review 84 (1): 255-270.

Siebert, R., M. Toogood, and A. Knierim. 2006. "Factors affecting European farmers' participation in biodiversity policies". Sociologica Ruralis 46 (4): 318-340.

Unay-Gailhard, İ., and Š. Bojnec. 2016. "Sustainable participation behaviour in agrienvironmental measures". Journal of Cleaner Production 138:47-58. 
Vickrey, W. 1961. "Counterspeculation, auctions, and competitive sealed tenders". Journal of Finance 16 (1): 8-37. 


\section{Appendix: Experimental instructions}

The experimental instructions for the discriminatory price treatment (D) are presented below. The experimental instructions for the endowed uniform price (U-endowed) and unendowed uniform price (U-unendowed) treatments are available upon request. They are very similar to the instructions for the D treatment. The key differences are in (i) successful bidders getting paid their bids or receiving the predetermined price (i.e. the auction design), and (ii) the way in which the bid question is formulated - as discussed in Section 2.

\section{INSTRUCTIONS:}

You are about to participate in an experiment on individual decision-making. Before we start, we would like to ask that you do not communicate with other people during this session. Please also turn off your mobile phone.

The experiment consists of two parts. The instructions for the first part, Part I, will be read out aloud now, and you are invited to read along. After completion of Part I of the experiment, you will receive the instructions for Part II, and then Part II will take place.

\section{INSTRUCTIONS FOR PART I:}

You receive a show-up fee of $€ 5$ for being here today. The mug that you just received, is yours. Depending on your decisions in Part I, you can take your mug home, but you may also decide to sell it back to the experimenters for a monetary payment.

Whether you take your mug home or sell it back for a payment in Part I is determined in a special kind of auction. In the auction format used in this session, the auction participants are not bidding to BUY an item, but to SELL an item. In this auction, you decide what price you are willing to sell your mug for. The price that you submit is called your bid.

There are 7 participants in your group, you and 6 other individuals in this room. All participants submit their bids simultaneously. That means that at the moment that you submit your bid, you do not know what bid any other participant submits.

After all participants have submitted their bids, the computer will rank all bids of the seven participants in your group from the lowest bid to the highest bid. We buy back the mugs from the participants who ask the lowest price in their bid.

If your bid is among the LOWEST four bids in your group, your bid is ACCEPTED in this auction. 
If your bid is NOT among the lowest four bids in your group (but among the highest three), your bid is NOT accepted in this auction.

The auction will not just take place once; it will be repeated ten times. However, you only have one mug that you can keep, or sell. We implement this as follows. After both Part I and Part II have been completed, the computer randomly selects which of the ten auctions you participated in in Part I, will be implemented.

If, in that randomly selected auction, your bid was NOT accepted (that is, if it was NOT among the LOWEST four bids in your group), you take your mug home, as well as the €5 show-up fee plus any earnings you receive in Part II.

If, in that randomly selected auction, your bid was ACCEPTED (that is, if it WAS among the LOWEST four bids in your group), you have to hand in your mug, but you receive the price that you stated in your bid, as well as the €5 show-up fee plus any earnings you receive in Part II.

All earnings will be paid to you via bank transfer within 48 hours.

Each of the ten auctions is independent, because the outcome of only one will be implemented.

We will now explain the auction rules that apply in each of the ten auctions you will participate in in more detail.

\section{THE PROCEDURES:}

Auctions take place with 7 participants in a group - you, and six other individuals in this room. You are matched with the SAME six participants in each of the ten auctions in Part I.

In each auction, you can bid any amount between 0.00 and 15.00 Euros. Bids can be in full Euros, but also in tens of euro cents. For example, you can bid Z Euros and 10 cents, Z Euros and 20 cents, etc., but not Z Euros and 15 cents, or $\mathrm{Z}$ Euros and 16 cents.

All participants submit their bids simultaneously. At the moment that you submit your bid, you thus do not know what bid any other participant submits.

After all participants have submitted their bids, the computer will rank the bids of the seven participants in every group from the lowest bid to the highest bid.

After the computer has ranked all bids of your group, you will be informed of the bids of the six other participants in your group. You will then also be informed whether your bid was ACCEPTED, or NOT. 
If your bid is ACCEPTED in this auction (that is, if it is among the LOWEST four bids in your group in this auction) and if, at the end of the session (after both Part I and Part II have been completed), this auction is randomly selected by the computer, you receive the price that you asked for in your bid, and you have to HAND IN your mug.

If your bid is NOT accepted in this auction (that is, if your bid is among the highest three bids in your group in this auction) and if, at the end of the session (after both Part I and Part II have been completed), this auction is randomly selected by the computer, you KEEP your mug, and you do not receive the price that you asked for in your bid.

In case of "ties", the computer will randomly determine which bids are accepted. If, for example, the $4^{\text {th }}$ and $5^{\text {th }}$ lowest bids are the same, the computer will randomly determine which of the two will be accepted. If the $3^{\text {rd }}, 4^{\text {th }}$ and $5^{\text {th }}$ lowest bids are the same, the computer will randomly determine which two of the three bids will be accepted, etc.

This completes the description of the auction. The procedure is repeated ten times. The outcome of each of the ten auctions is thus whether your bid was ACCEPTED, or NOT, and one of these ten outcomes will be implemented at the end of the session. As stated before, the other bidders in all the auctions you participate in, are always the same six individuals.

Let us now have a look at the screens. 


\section{SCREENS:}

The first screen is the following.

SCREEN 1:

Auction of 10

My bid in the auction is $€ X$.X.

If my bid is among the 4 lowest bid

my group, I sell my mug for

Otherwise. I keep my mug.

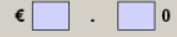

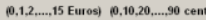

Enter a value between $€ 0.00$ and $€ 15.00$

rounded to tens of euro cents.

Update value

Help

Please select a value for your bid. Enter a value for euros in the lent field and a value for tens of euro cents in the right field. Click on the 'Update value' button to display your selected value for $\epsilon$ Xx(this is not your final decision). If you are absolutely sure that this should be your bid in this auction, then click on the "Submit bid" button.
You can updatete your bid as many times as you want Clicking the "Submit bid' bution makes the chosen value your final bid for this auction.

On the top-left part of this screen, you are informed about which of the ten auctions you now participate in. On this screen you are requested to submit a bid. You can enter a value for Euros (in round numbers, 0, 1, 2, .., 15) in the left field and a value for euro cents (in multiples of ten cents, $0,10,20, \ldots, 90$ cents) in the right field - note that the 0 is preprinted, so enter " 1 " if you want to enter "10 cents". Suppose you entered a bid of X.x0 Euros. After clicking on the "Update value" button, the next screen will appear. 


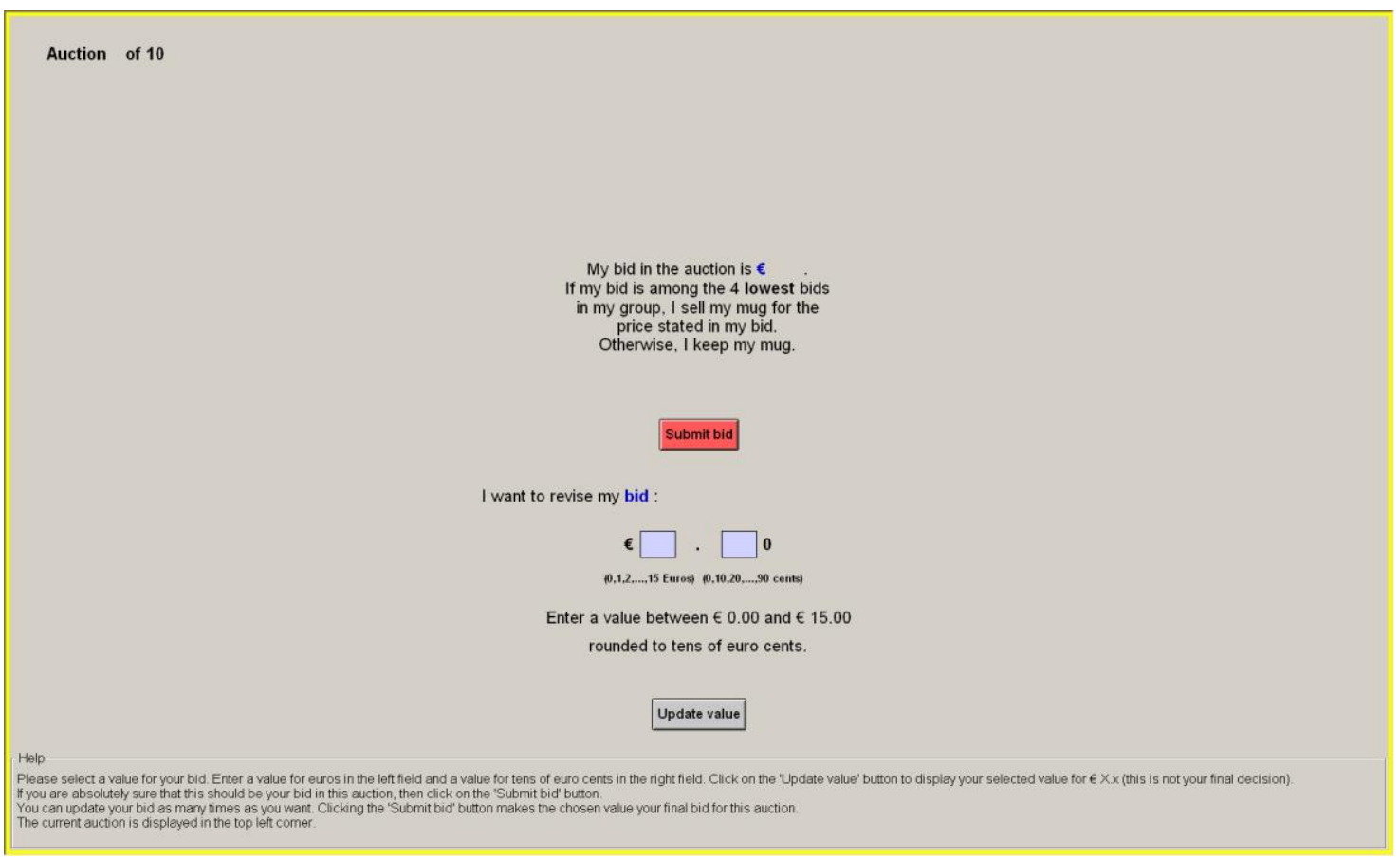

The bid that you entered will appear in the top line on the screen. If you are certain that you want to bid this amount, then click on the "Submit bid" button in the middle of the screen. Your bid will then be entered on your behalf in this auction. If, however, you want to revise the number you entered, do not press the "Submit bid" button yet. Instead, enter the revised number in the squares in the lower half of the screen, and press the "Update value" button. Then the screen will be refreshed, and you have again the choice between "Submit bid" and "Update value". You can revise your bid as many times as you want before finalizing it. Clicking the "Submit bid" button makes the chosen value your final bid for this auction.

After you and all other participants have clicked the "Submit bid" button, the computer ranks all seven bids in your group. Depending on whether or not your bid is among the lowest four bids in your group, one of two screens will appear. 
Example 1. Suppose that your bid is NOT among the four LOWEST bids in your group. Then the following screen will appear.

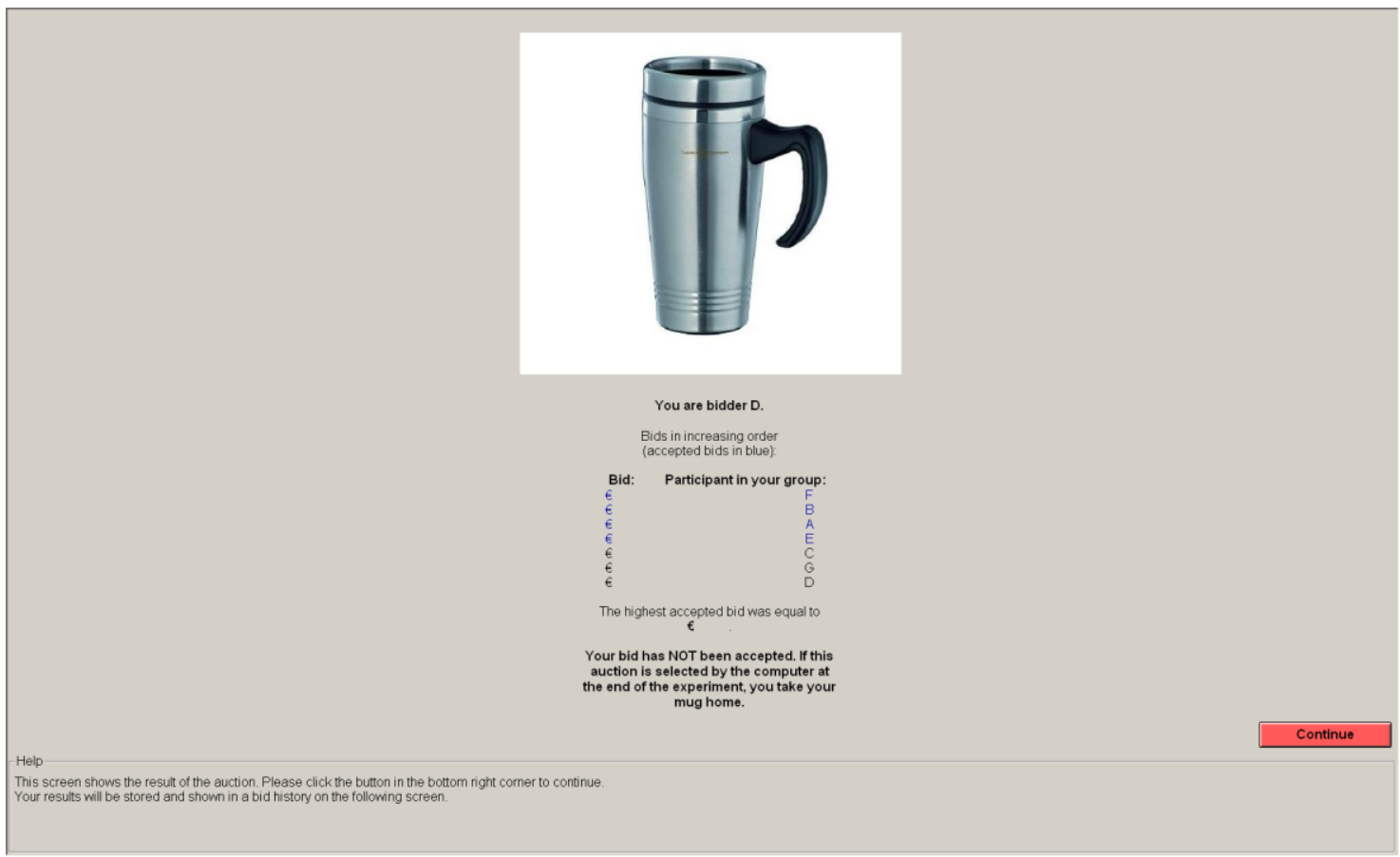

On this screen, you are informed about the bids of all seven participants in your group, and also what the $4^{\text {th }}$ lowest bid was - the highest bid that was accepted in this auction. You are also informed that your bid has NOT been accepted in this auction, because in this example we assumed that your bid was NOT among the four lowest bids in your group. That means that if, at the end of this session (after Part II has been completed too) the computer randomly selects this auction, you KEEP your mug and you can take it home with you.

In the bottom right corner, you can click on the "Continue" button to proceed to the next auction. We will come back to this after the second example. 
Example 2: Suppose that your bid IS among the four LOWEST bids in your group. Then the following screen will appear.

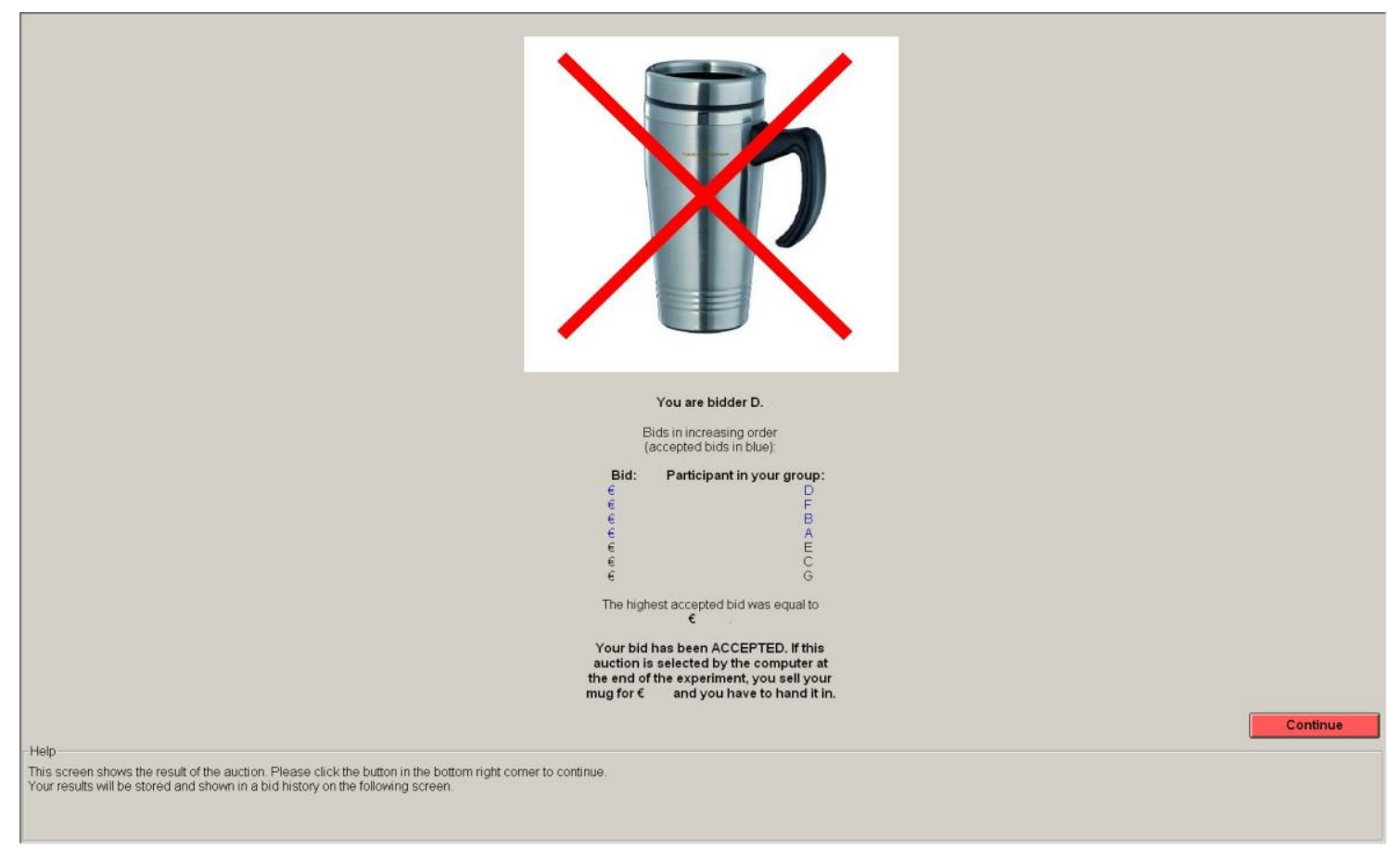

Of course, this screen is very similar to the previous one. You receive the same information. That means that you are informed about the bids of all seven participants in your group, and also what the $4^{\text {th }}$ lowest bid was - the highest bid that was accepted in this auction. However, in this case, you are informed that your bid has been ACCEPTED in this auction, because in this example we assumed that your bid was among the lowest four bids in your group. That means that if, at the end of this session (after Part II has been completed too) the computer randomly selects this auction, and you have to HAND IN your mug. You do receive the price that you asked for in your bid.

In the bottom right corner, you can click on the "Continue" button to proceed to the next auction. The screen that will appear looks the same as Screen 1, except that in the top right corner of that screen, you will see the history of your bid decisions and auction outcomes in all previous auctions.

This completes the description of the screens.

Are there any questions at this point? Please raise your hand, and we will come to you to answer your questions.

If there are no further questions, we now continue with a short test. Please answer the following questions. When you have finished answering them, please raise your hand and we will come by to check your answers. 


\section{TEST QUESTIONS PART I:}

1. In Part I, you participate in 10 auctions. The six other participants in one auction are not necessarily the same individuals as the six participants you are matched with in another auction. $\mathrm{Y} / \mathrm{N}$

2. After you have entered your bid and pressed the "Update value" button, you can no longer revise it. $\mathrm{Y} / \mathrm{N}$

3. After you have pressed the "Submit bid" button, the value that is shown on the top line of the associated screen is the bid that you entered. You can no longer revise it. $\mathrm{Y} / \mathrm{N}$

4. Please circle the correct option. Suppose that, in an auction, your bid is the lowest bid. If, at the end of the session, this auction is randomly selected by the computer, you

a) can take your mug home with you, but you do not receive the amount of money that you asked for in your bid.

b) have to hand in your mug, but you do receive the amount of money that you asked for in your bid.

5. Please circle the correct option. Suppose that, in an auction, there are three participants that bid an amount smaller than your bid, and the bids of the remaining three participants are higher than your bid. If, at the end of the session, this auction is randomly selected by the computer, you

a) can take your mug home with you, but you do not receive the amount of money that you asked for in your bid.

b) have to hand in your mug, but you do receive the amount of money that you asked for in your bid.

6. Please circle the correct option. Suppose that, in an auction, there are four participants that bid an amount smaller than your bid, and the bids of the remaining two participants are higher than your bid. If, at the end of the session, this auction is randomly selected by the computer, you

a) can take your mug home with you, but you do not receive the amount of money that you asked for in your bid.

b) have to hand in your mug, but you do receive the amount of money that you asked for in your bid. 


\section{INSTRUCTIONS FOR PART II:}

In this second and last part of the experiment, you participate in a similar auction as in Part I. In this auction, the item you can decide to sell is NOT the mug on your desk. The item is a "virtual good": a token.

At the beginning of Part II, you will be informed what the value is of your virtual token. This value is expressed in points.

In this Part II, 1 point is worth 5 euro cents. 100 points are thus worth 5 Euros.

The value of your virtual token is randomly selected from a range between 0 and 150 points. The value is drawn independently for each participant.

In the auction, you can decide for how many points you are willing to sell your virtual token. The number that you submit is called your bid.

In this auction, there are again 7 participants; you and six others. The six others are NOT the same six individuals as in Part I. The computer will randomly rematch all participants in groups of 7 at the beginning of Part II.

You can bid any number between 0 and 150 points. The computer ranks the bids of all seven participants in your group from the lowest bid to the highest bid. All participants submit their bids simultaneously. That means that at the moment that you submit your bid, you do not know what bids are submitted by any other participant.

If your bid IS among the lowest four bids in the auction, your bid is ACCEPTED. You sell your virtual token, and you receive a payment equal to the number of points that you asked for in your bid.

If your bid is NOT among the lowest four bids in the auction, your bid is NOT accepted. You keep your virtual token, and you receive the value of your virtual token that you were informed about at the beginning of Part II.

In this Part II there is JUST ONE auction. After all participants have submitted their bids, you are informed of the outcome of the auction you participated in, and you are informed about your earnings in this Part II.

This completes the description of Part II.

Next, the computer will randomly select which of the 10 auctions you participated in in Part I is implemented. You will be shown the outcome of that auction. Then the experiment is completed.

As stated before, all earnings will be paid to you via bank transfer within 48 hours.

This completes the description of the session. Let us now have a look at the screens of Part II. 


\section{SCREENS:}

The first screen is the following.

SCREEN 1:

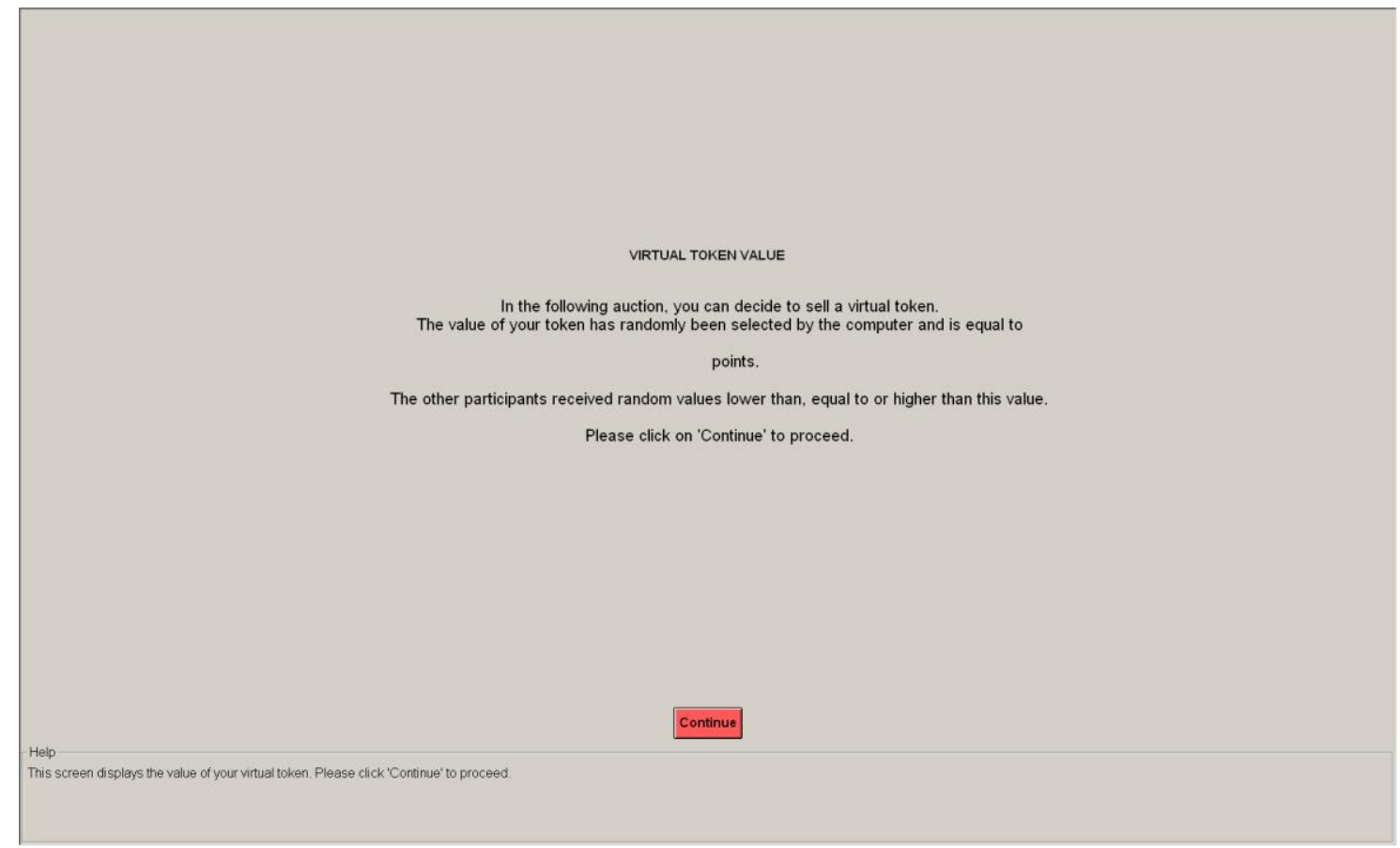

This screen informs you about value of your virtual token. The computer assigns a random value between 0 and 150 points to the virtual token of each participant. The value assigned to the virtual token of each of the other six participants in your group is thus unlikely to be the same as the value assigned to your virtual token. Click the "Continue" button to proceed to the next screen. 
SCREEN 2:

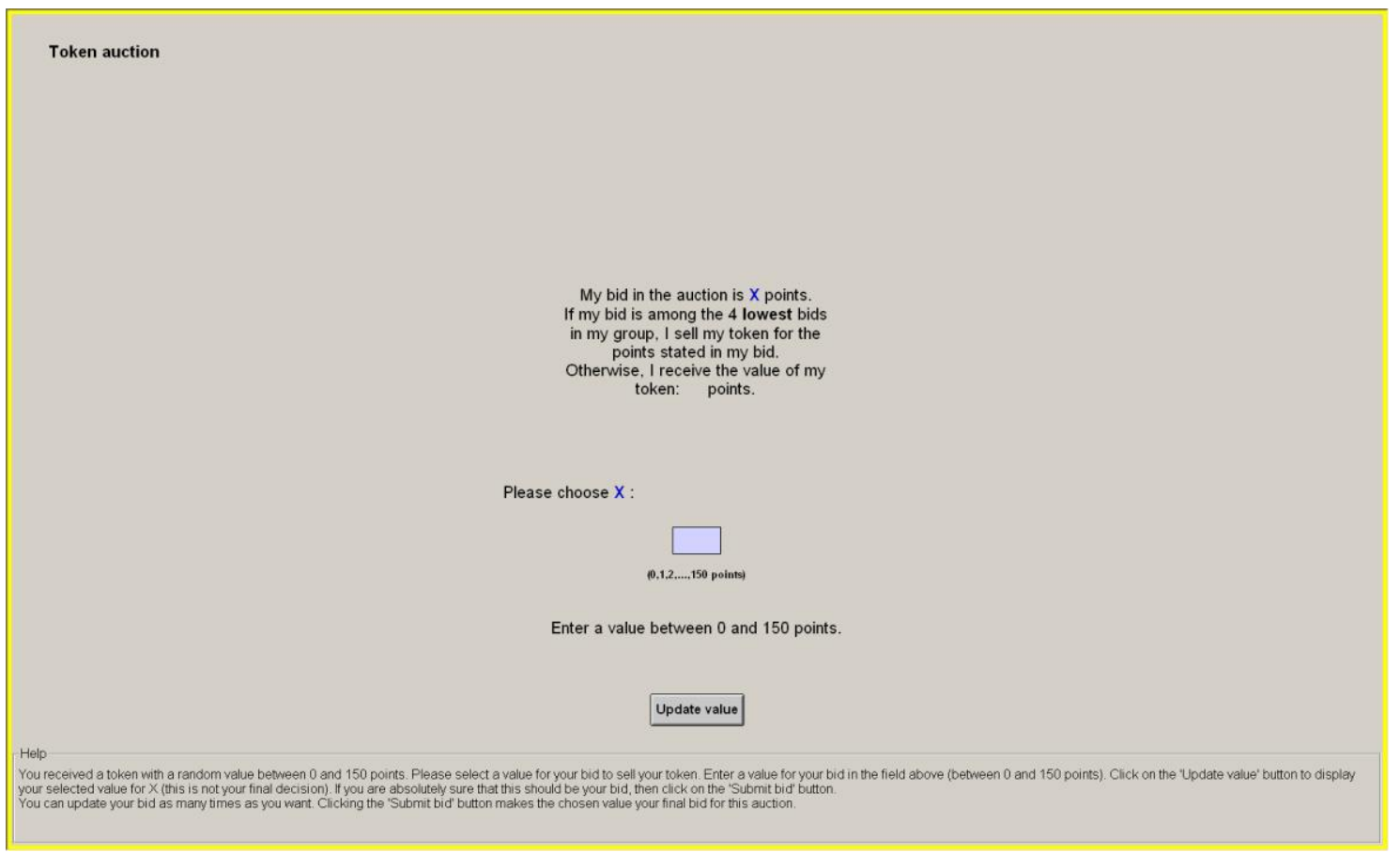

In this screen, you are requested to submit a bid. You can enter your bid (between 0 and 150 points) in the square field. Upon clicking the "Update value" button, the next screen appears. 


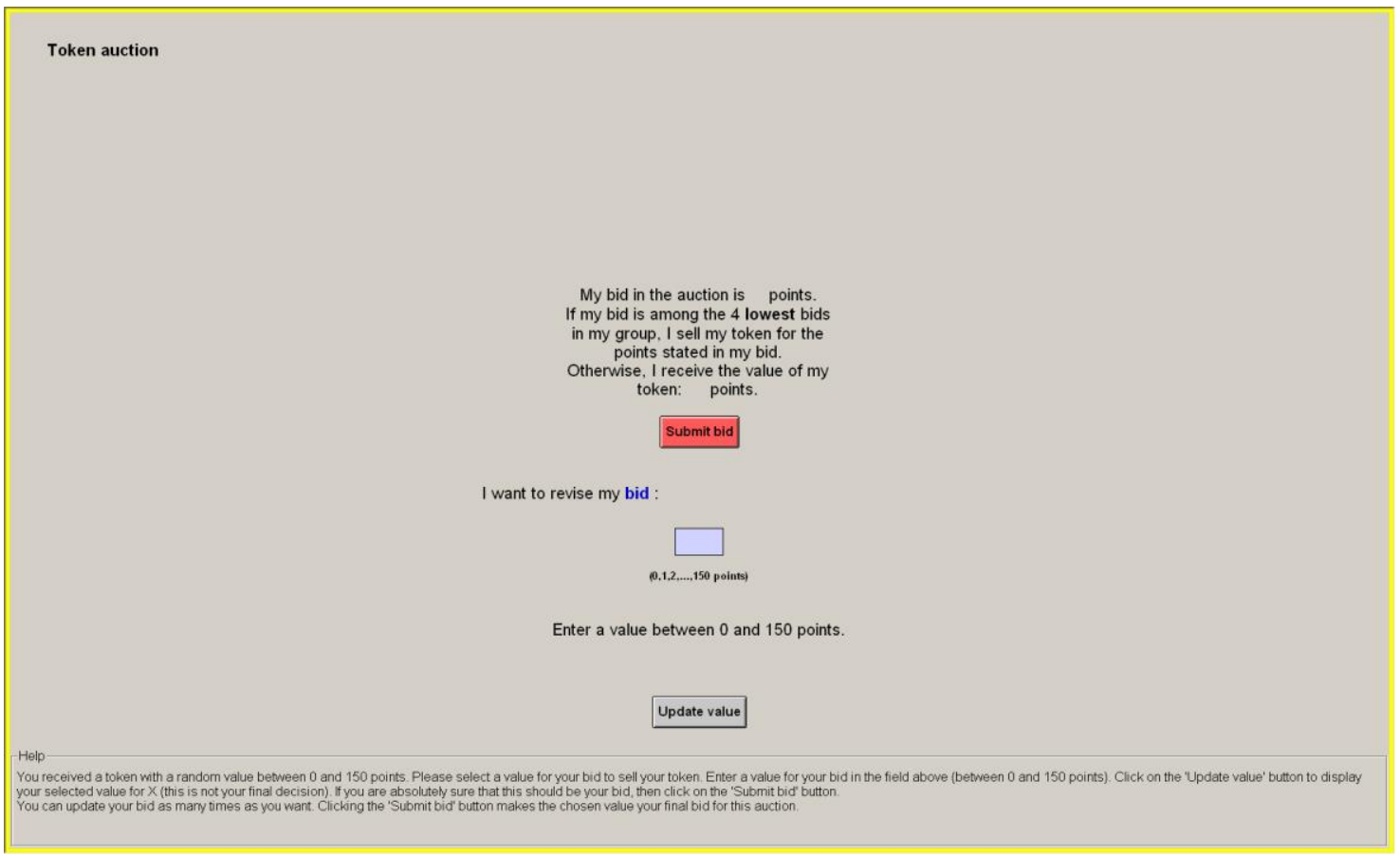

The bid you entered is shown on the top line. If you indeed want to submit this bid, press "Submit bid". If you want to revise your bid, enter a new number in the field, and press "Update value" again. You can revise your bid as many times as you want before finalizing it. Clicking the "Submit bid" button makes the chosen number your final bid for this auction.

After you and all other participants have pressed "Submit bid", the computer ranks all seven bids in your group. Depending on whether or not your bid is among the lowest four bids in your group, one of two following screens will appear. 
Example 1. Suppose that your bid is NOT among the four LOWEST bids in your group. Then the following screen will appear.

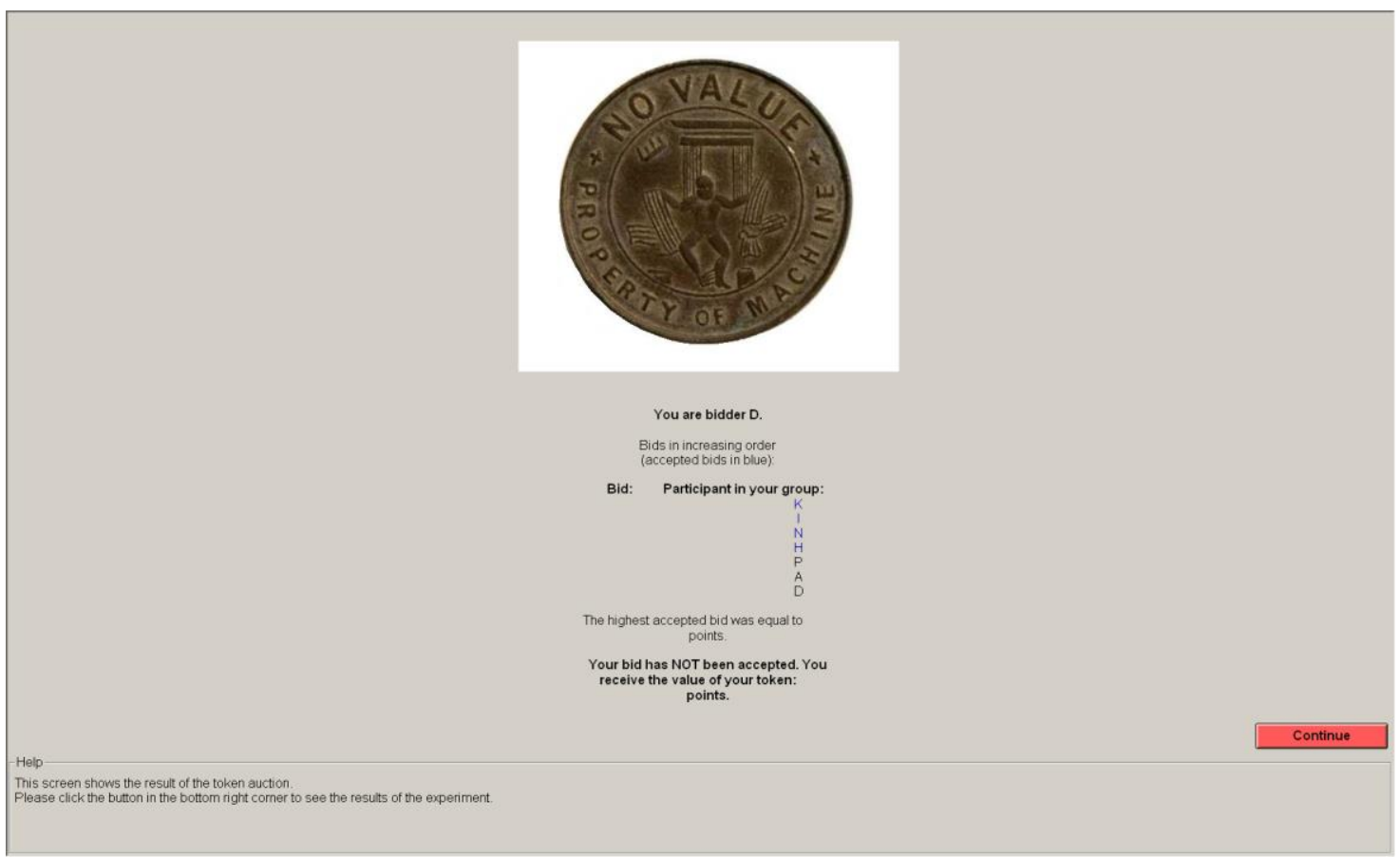

On this screen, you are informed about the bids of all seven participants in your group, and also what the $4^{\text {th }}$ lowest bid was - the highest bid that was accepted in the auction. You are also informed that your bid has NOT been accepted in this auction, because in this example we assumed that your bid was NOT among the four lowest bids in your group. That means that you do NOT sell your virtual token, and that your Part II earnings are equal to the value of your virtual token, as was conveyed to you in Screen 1 of Part II.

In the bottom right corner, you can click on the "Continue" button to finish the auction and proceed to a screen that summarizes your results in Part I and II. We will discuss this in a moment. 
Example 2: Suppose that your bid IS among the four LOWEST bids in your group. Then the following screen will appear.

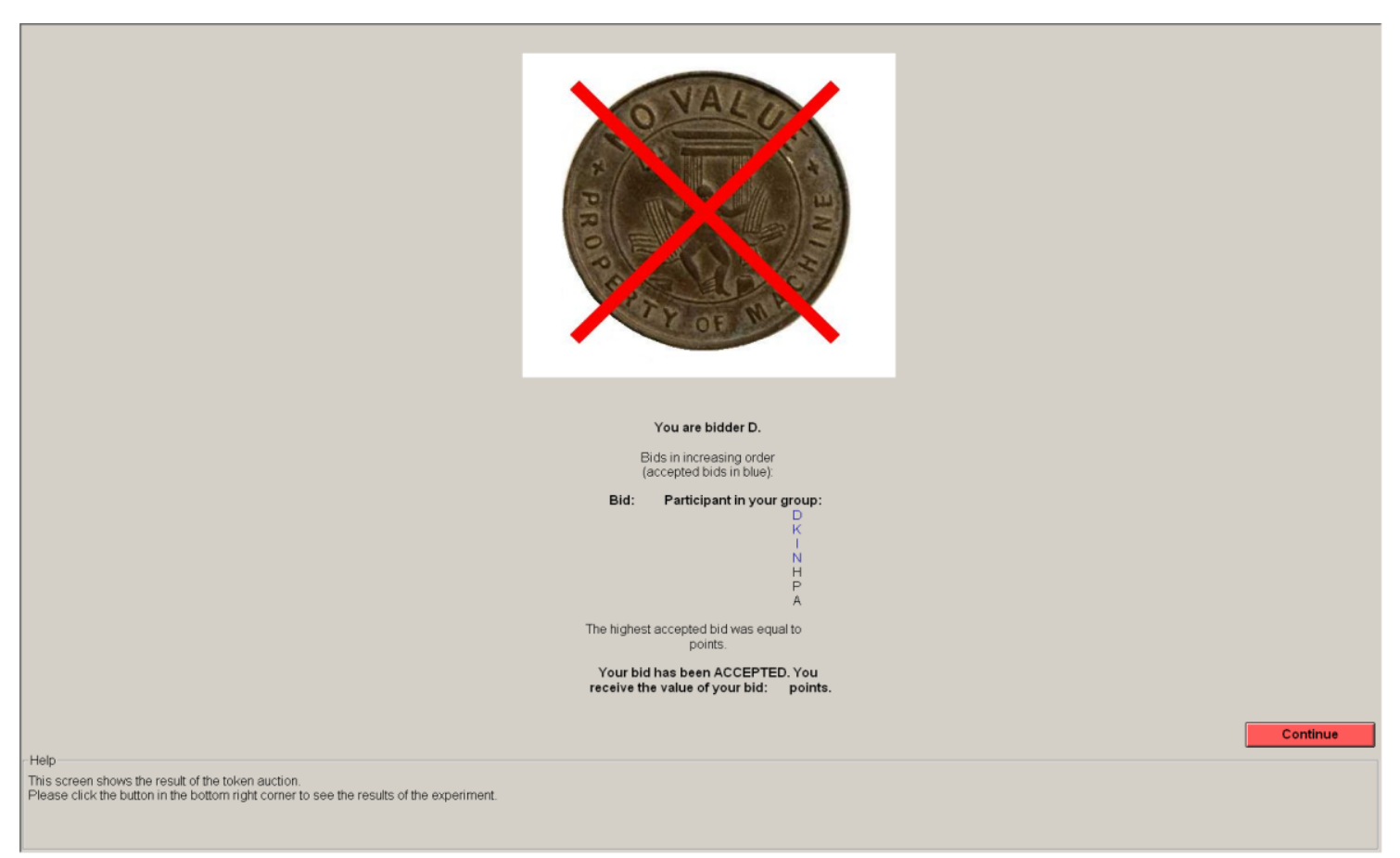

This screen is very similar to the one before. You are informed about the bids of all seven participants in your group, and also what the $4^{\text {th }}$ lowest bid was - the highest bid that was accepted in the auction. However, in this case, you are informed that your bid has been ACCEPTED in this auction, because in this example we assumed that your bid was among the lowest four bids in your group. That means that you SELL your virtual token, and that your Part II earnings are equal to the bid that you submitted.

In the bottom right corner, you can click on the "Continue" button to finish the auction and proceed to a screen that summarizes your results in Part I and II. It will also show you which auction of Part I is randomly selected to be implemented, and what your total earnings are in this session.

This completes the description of the screens.

Are there any questions at this point? Please raise your hand, and we will come to you to answer your questions.

If there are no further questions, we now continue with a short test. Please answer the following questions. When you have finished answering them, please raise your hand and we will come by to check your answers. 


\section{TEST QUESTIONS PART II:}

1. In Part II, you participate in only one auction. The six other participants in this auction are the SAME six individuals you were matched with in the auctions in Part I. Y/N

2. Please circle the correct option. In Part II, the item that is auctioned, is

a) the mug in front of you.

b) a virtual good: a token.

3. After you have entered your bid and pressed the "Update value" button, you can no longer revise it. $\mathrm{Y} / \mathrm{N}$

4. After you have pressed the "Submit bid" button, the value that is shown on the top line of the associated screen is the bid that you entered. You can no longer revise it. $\mathrm{Y} / \mathrm{N}$

5. Please circle the correct option. If my bid in Part II is ACCEPTED, I receive

a) the value of my virtual token that I was informed about at the beginning of Part II.

b) the number of points I asked for in my bid.

6. Please circle the correct option. If my bid in Part II is NOT accepted, I receive

a) the value of my virtual token that I was informed about at the beginning of Part II.

b) the number of points I asked for in my bid. 